\title{
Les Cahiers de l'École du Louvre
}

Recherches en histoire de l'art, histoire des civilisations, archéologie, anthropologie et muséologie

3 | 2013

Cahiers 3

\section{Éditorial}

\section{Collectif}

\section{OpenEdition}

Journals

Édition électronique

URL : http://journals.openedition.org/cel/496

DOI : $10.4000 / \mathrm{cel} .496$

ISSN : 2262-208X

Éditeur

École du Louvre

Édition imprimée

Date de publication : 1 octobre 2013

Référence électronique

Collectif, «Éditorial », Les Cahiers de l'École du Louvre [En ligne], 3 | 2013, mis en ligne le 01 octobre 2013, consulté le 23 septembre 2020. URL : http://journals.openedition.org/cel/496 ; DOI : https:// doi.org/10.4000/cel.496

Ce document a été généré automatiquement le 23 septembre 2020.

\section{c) $($ ) $\odot$}

Les Cahiers de l'École du Louvre sont mis à disposition selon les termes de la licence Creative Commons Attribution - Pas d'Utilisation Commerciale - Pas de Modification 4.0 International. 


\section{Éditorial}

\section{Collectif}

1 Pour leur troisième livraison, les Cahiers de l'École du Louvre se dotent de deux nouvelles rubriques : un dossier thématique d'articles et un espace consacré à l'« Actualité de la recherche » à l'École du Louvre.

2 C'est Hélène Klein, conservateur en chef du patrimoine, encadrant à l'École un groupe de recherche sur des revues d'art du $\mathrm{xx}^{\mathrm{e}}$ siècle qui inaugure le dossier. Son introduction aux quatre articles dédiés aux revues Broom, Documents, Labyrinthe et L'Élan expose les différentes approches méthodologiques suscitées par un tel objet d'étude et montre combien le dépouillement et l'analyse approfondie de ces revues dans leur contexte de production offre une clef de lecture privilégiée, riche et passionnante de l'art contemporain.

3 La rubrique «Actualité de la Recherche » entend faire un bilan de ce qui fait et nourrit la recherche à l'École. Comptes rendus de cycles de conférences et de journées d'études organisées par les élèves, par l'équipe de recherche, ou par des institutions extérieures. C'est là que s'intégreront annuellement la liste des dépôts de sujets de recherche de $3^{\mathrm{e}}$ cycle et les positions des thèses soutenues.

4 Le présent numéro livre la conférence John Constable et le statut de l'esquisse de John Murdoch, chercheur invité, lauréat de la bourse de la Fondation Daniel et Nina Carasso, le compte rendu de la première journée d'études élaborée par les élèves de troisième cycle en muséologie sur "Reconnaissance et médiation d'un patrimoine: vecteurs d'une identité nationale?", ainsi qu'une présentation des conférences des Ymagiers organisées par l'Institut de recherche et d'histoire des textes (CNRS) accueillis, depuis octobre 2013, à l'École du Louvre.

L'Équipe de recherche. 